\section{How dialogue and} democracy evolve through the interactions of children

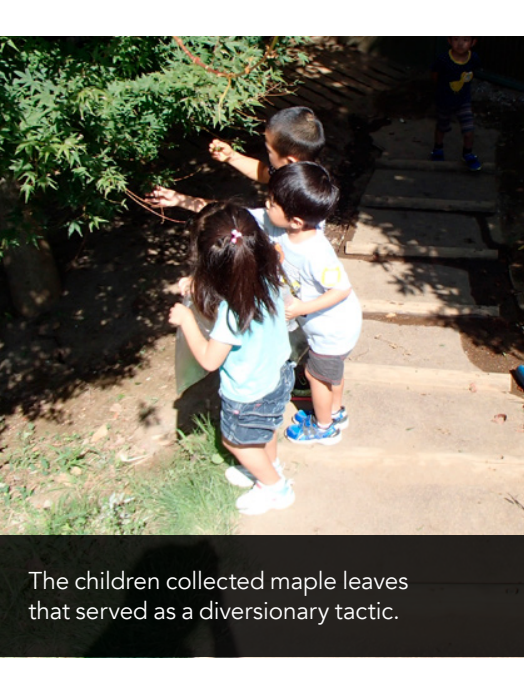

It used to be said that children should be 'seen and not heard'. However, since 1989 the United Nations enshrined childcentred education into its core values, and this educational style is now the norm for many as human beings with individua rights and agency, this style of education aimed to change how society views and treats children. Yuta Miyamoto of the University of Fukui examines children's voices during their dialogue-based problemsolving process and has been democracy evolve in children's early years. were encouraged to discuss their performance and strategies to win. The he United Nations Convention on
the Rights of the Child shows the
the datations and actions, he analysed child's right to express opinions, developed among the children and and the understanding that every child has agency and should be an equal participant in everyday life. New research help children find their voices and learn to listen to and work with others from an early age. Yuta Miyamoto, a senior assistant professor at University of Fukui and a collaborative researcher at the University of Tokyo (Cedep), is particularly interested in how dialogue and democracy evolve in young childre and how teachers can help them develop social capacity. He has been exploring the possibilities of children's voices in

their own dialogue.

A former early years' teacher himself Mr Miyamoto conducted his researc by observing classes of four-year-old children as they engaged in specific whole-group activities over a period of
weeks. After recording their participation

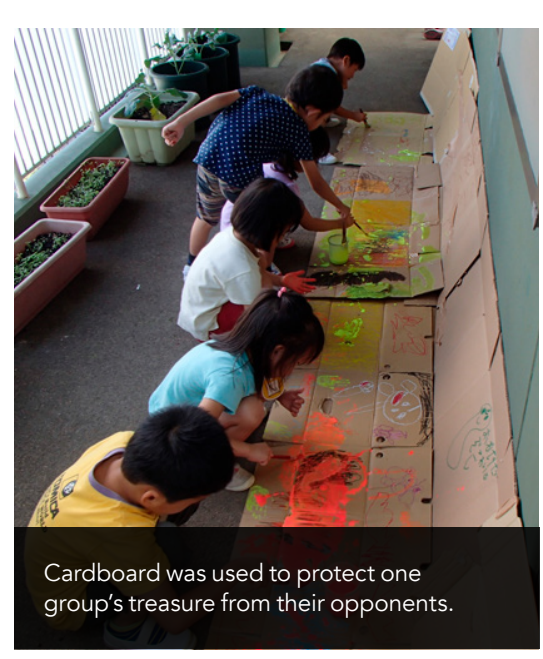

amiliar in their classroom activities. Item of treasure were placed in the centre of the feld and he two classes were each given a designated area at he side. The cildren had to collect items of treasure when no more tems were left in the centre, the children could take them from the other group's collection. The aim was to collect as much treasu as possible in three minutes and the group with the most items won.

The children initially accepted that they had either won or lost. However, the game was repeated, and the children teacher's role was to initiate discussion and guide the children's thinking rath than express ideas or offer advice. Miyamoto recorded the children's dialogue and behaviour in these between fiventing wich each took between five and this also looked a thow the teacher interacted with the children.

\section{DEMOCRACY IN ACTION} Miyamoto said: "Children began to talk about strategies for winning. They shared their opinions through their own Pasperiences and memories of them Passion ignited the class atmosphere creating a polistened to each orty and connection."

The conversations recorded by the author revealed surprising insights about the importance of democratic participation in which children as agents have rights distracted by the noise coming opposing team. This prompted another

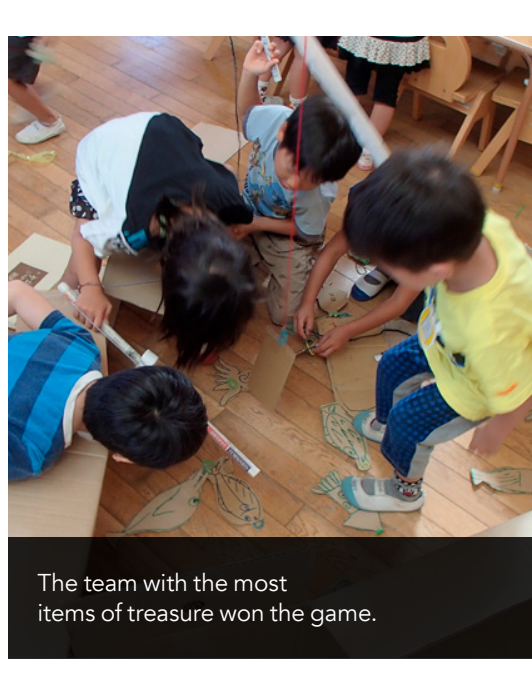

to suggest that next time they should also yell. However, this upset someon else who said she did not like yelling, so a founth chld suggested a different The teacher said this was interesting The teacherid this was intersing got hit by sand. A fifth child then suggested they should throw maple leaves on the ground. When a sixth child pointed out that 'maple' was the name of their opponent's class, the group quickly agreed on this course of action, clearly satisfied with their group decision.

Mr Miyamoto explained: "This strategy was the children's original and unique

The group began to understand the significance of making plans and carrying them out with friends.

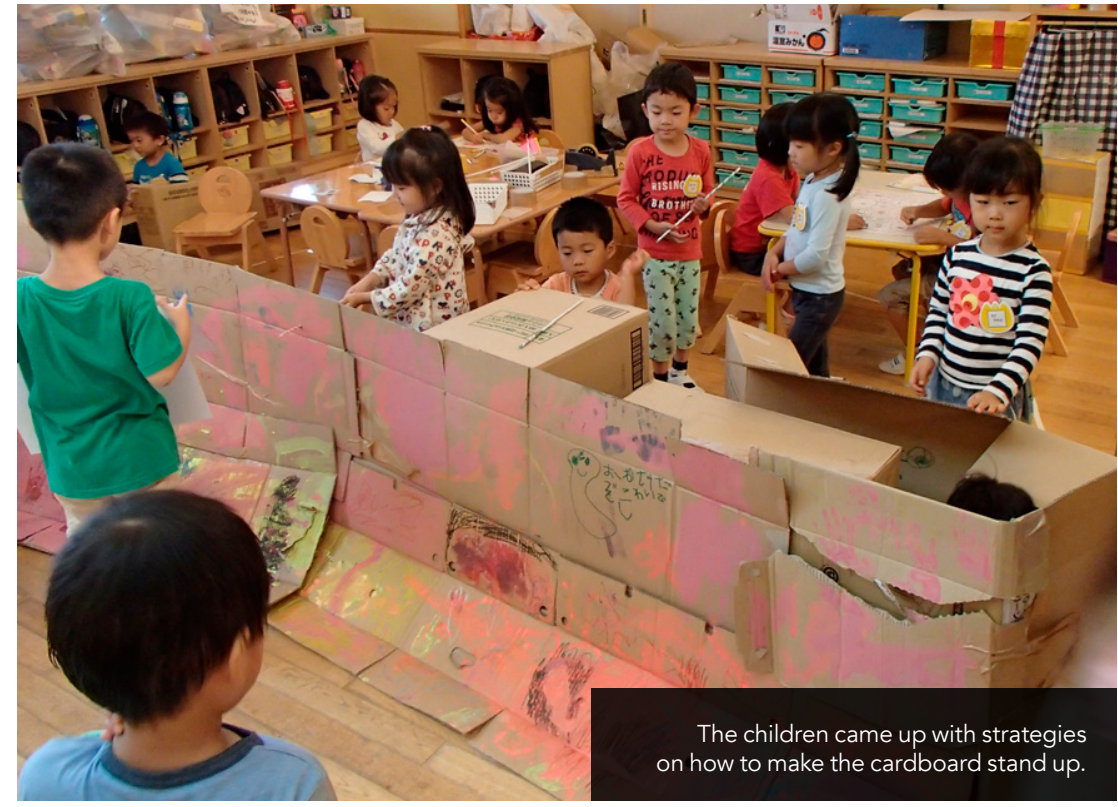




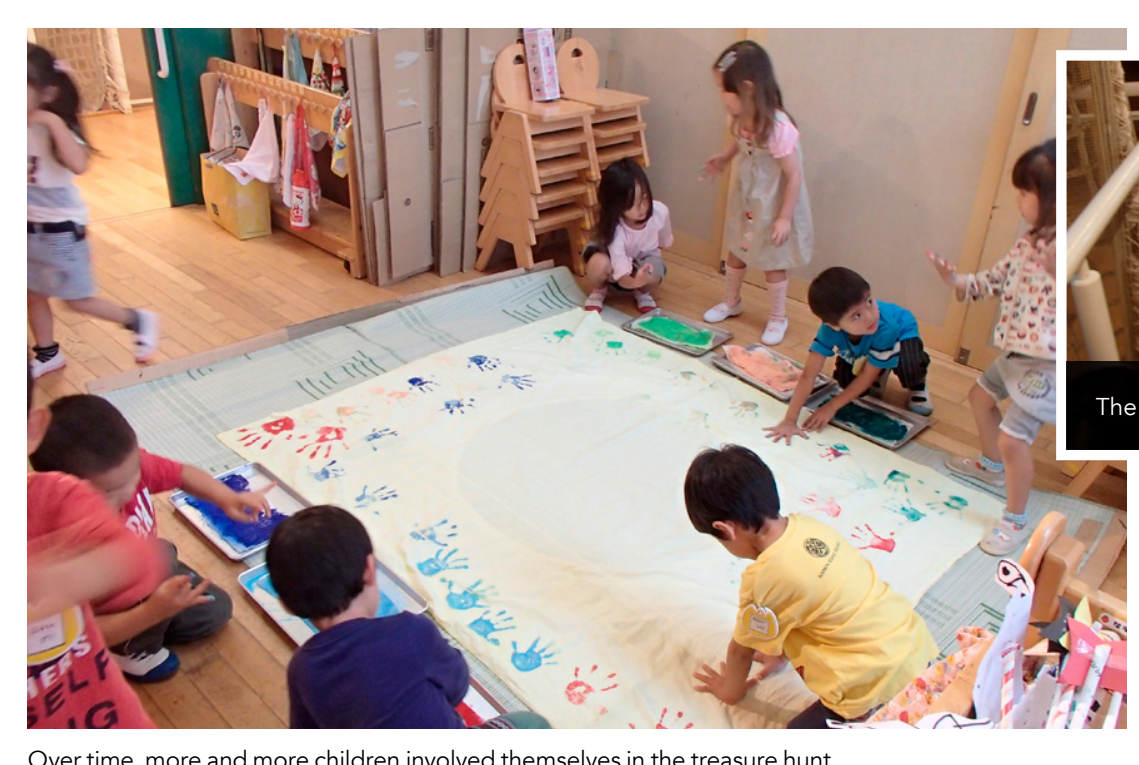

idea. As the group followed up on the suggestions made by the map shared discussion, the group bega to understand the significance of making plans and carying them out with friends. Teachers refrained from expressing their own opinions, caring only about three points: developing the children's curiosity; enjoying the uncertainty of the situation; and respecting subjectivity.

\section{TACTICAL THINKING} dicated that the children were beginning to consider how they might work together tactically. One child proposed they should protect their treasure to prevent it from

the human wall. It was very interesting but did not lead to a discussion of how the strategy would work at the match level. This discussion evolved into a practical strategy over the course of the actual game. They moved on to oniderations such as how to make the cardboard stand up. The author explained: "The meeting style shifted from one in which only a few children participated, to one in which many children expressed their opinions. This seemed to indicate a collective consciousness towards their common goal."

It also showed that sharing common daily experiences, such as how cardboard can

For them, this game became their own play. This is how the children grew, tested and explored - through democratic meetings and experiences.

another proposed they should "make a plan" which they developed at their next meeting

The teacher began by asking how the class felt about losing previously. This elicited comments such as "sad and frustrated". The children clearly felt emotionally connected to their treasure it The bad when their opponents took it. The plan they devised was to form a wall to prevent their treasure from beeng
taken. They had a discussion about is important in the consensus building process. Mr Miyamoto added: "From an adult perspective, those strategies However, the children were always serious. Their eyes began to brighten as they came up with new and interesting strategies and they began to move into action with their friends. For them this game became their own play. This and experiencess" seemed impractical and meaningless. is how the children grew, tested and

\section{THE PERFORMANCE} The children played their treasure hunt game in front of parents at the Sports Festival Day. The games ended in a draw, but the children looked happy to have done everything they could

Afterwards a parent commented: "My child was always talking to us seriously boun this game a home, but ldidn't watched the game and finslly connected everything... I found it led to the children's development because the teacher valued the processes involved, such as the children interacting with each other... (it was) an enjoyable and powerful day." The children's use of strategy in this game involved their parents and engrossed them.

\section{CONCLUSION}

Mr Miyamoto's research shows that children as young as four can engage in democratic practice and interaction and demonstrate consensus-building in how children can be hel tho illustrates vice and how careful guidance from the teacher can elicit dialogue.

The author explained: "Believing in children's potential requires teachers to be facilitators of children's experiences and communication... Democratic practices require reflective teachers to accept the curiosity, inquiring minds and sensibilities of children whilst evaluating what children try, do and know."

He added: "The findings capture how the discovery of children's potential can occur through careful observations that focus on expressions, feelings and acquistion of new ideas. Examples analysed demonstrate that sistoning toctice demonstrate that lstening to children is adults ic process involing children and

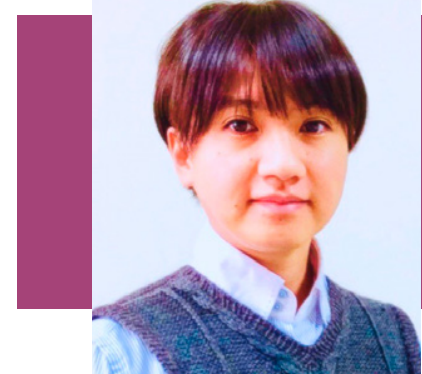

\section{Behind the Research} Yuta Miyamoto

E: yuta-mt@u-fukui.ac.jp T: +81 776230500

\section{Research Objectives}

Yuta Miyamoto examines how dialogue and democracy evolve in the interactions of young children.

\section{Detail}

Yuta Miyamoto

3-9-1, Bunk yo

Fukui 910-8507

Fukui 910

Bio

Yuta Miyamoto is a senior assistant professor of University of Fukui, Japan. He has worked at the national government and as a kindergarten teacher. Now, he is concerned with fostering children's participation and and sense of unity in whole-group activities.

Funding

Japan Society for Promotion of Science KAKENHI GRANT NUMBER JP17J08823 (2017.4.1-2020.3.31).

\section{Acknowledgment}

. support of the Japan Society for the Promotion (2017.4.1-2020.3.31)

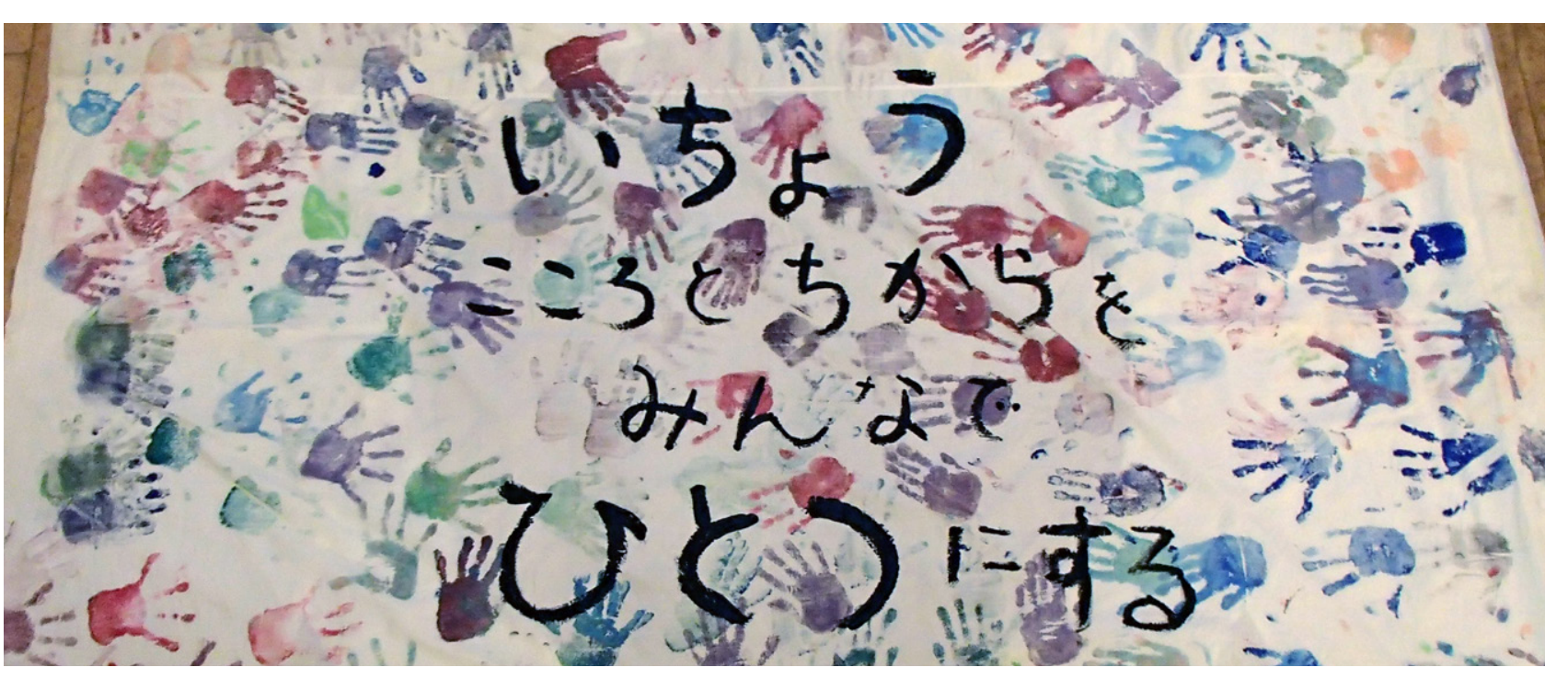

\section{References}

Miyamoto, Y. (2019). Japan: The Exploration of FourYear-Olds Potential, Focusing on the Democratic Meeting During the Sports Festival Day. Children's Self-determination in the Context of Early Childhood Cducation and Services, Contextional Perspectives on Eally

\section{Personal Response}

Your research suggests that many children engaged in the democratic meetings you observed. Approximately what proportion of the classes leaders and followers in the two groups?

II These democratic meetings gradually increased in the number of participants as each individual experience deepened. It takes time for each child to in this group like to give their opinions, others listen to them to deepen their thoughts, and still others are good at giving form to their ideas. Intercommunicating to participate. Therefore, the democratic meetings generated the value of diversity.

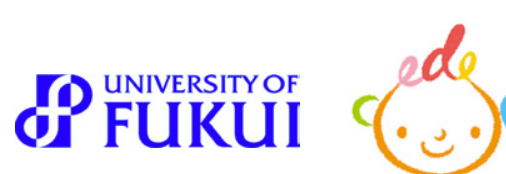
II 